\title{
Determining the Capacity of Combined Distribution Generation Resources in an Independent Distributed Network Considering the Uncertainty Behavior of Load and Energy Resource
}

\author{
Masoud Ghazipour Shirvan ${ }^{1 *}$ and Ali Asghar Ghadimi ${ }^{2}$ \\ 'Department of Electrical Engineering, Science and Research Branch, Islamic Azad University, Arak, Iran; \\ Ghazipour50@gmail.com \\ 2Department of Electrical Engineering, Arak University, Arak, Iran; a-ghadimi@araku.ac.ir
}

\begin{abstract}
This paper deals with the selection type and capacity of hybrid DGs in a stand-alone distribution system considering random behavior of loads and generators in augmenting renewable energy sources. Two methods were used to determine the capacity: by using Deterministic Parameters irrespective of stochastic behavior of loads and generators; the other was by considering the random behavior of renewable energies and loads. The objective is to minimize the cost and reliability constraint problem. In fact, the problem of capacity determination is expressed as a non-linear optimization problem. The combination of considered DG is wind, solar and battery that is independent from the network. The capacity was determined with respect to random behavior of DG and load. We used the Probability Density Function for DG and sequence Monte Carlo Method for load determination. Intelligent Algorithm (PSO) was used to find out the optimal capacity of DGs. All of the simulations were made in MATLAB software.
\end{abstract}

Keywords: Wind Energy, Solar Energy, Battery, Monte Carlo, Algorithm of Particle Mass.

\section{Introduction}

Due to environmental issues and efforts to reduce greenhouse gases, the renewable energy approach gains importance. Among renewable energy sources, wind and solar energies are considered much. These renewable energies are used in two forms [1]: Grid Connected Mode and Independent Electricity Network. In Grid Connected Mode, these units are used in order to strengthen the power grid, compensate voltage drop and line loss. But renewable generations are having problems as they have dependence on climatic conditions. This in turn leads to fluctuations in output. To resolve this problem a combination of energy sources are used together. This combination creates greater reliability and less fluctuation [2]. For example, a combination of wind and solar units. During winter and autumn, solar energy becomes less but sufficient wind energy does occur. In spring and summer, there would be more solar energy but less wind energy. Thus the mix of such renewable sources could complement each other. The problem of determining capacity of hybrid wind, solar and storage battery has been resolved with minimization cost, pollution index and reliability supply [3]. The problem of determining capacity of hybrid renewable units is expressed as a multi objective optimization problem [4].

${ }^{*}$ Corresponding author:

Masoud Ghazipour Shirvan (Ghazipour50@gmail.com) 
In this paper, electric power is supplied by independent network composed of wind, solar and battery units. The objective function is minimization of the annualized cost system and the minimization of the Loss of Power Supply Probability (LPSP) [4]. We used an optimal sizing model to optimize the capacity sizes of hybrid photovoltaic/wind power generation system using a battery bank. The objective function is 'cost', which is expressed as a levelised unit electricity cost model [5]. The power generation is calculated using hourly data of wind speed and solar radiation. The combination of wind units, electrolyzers and battery independent of network were used to provide the needed hydrogen transport in Norway and the problem of uncertainty of distributed generations was investigated [6].

The capacity of independent DG was determined by considering the stochastic behavior of load and energy resource. Two methods were used to determine the capacity; one by using deterministic data without considering the random behavior of renewable energies and loads; the other was by considering the random behavior of renewable energies and loads.

\section{Method of Solution}

The variable optimizations considered in this paper are: number of wind plants, solar plants and batteries. The primary function of optimizing the capacity determination is the cost function. Providing favorable reliability is considered as an optimization constraint. The objective of this optimization algorithm is to determine capacity of renewable units and storage system, so as to provide considered reliability with minimum cost. Reliability constraint that was considered in this paper is equal or less than reliability index from a constant value.

\subsection{Load Modeling using Monte Carlo Method}

Monte Carlo method was employed in modeling the behavior of the system. Ascertained algorithms for Monte Carlo method is as follows: after generation of the Probability Density Function (PDF): wind speed, solar radiation and load, which are the first population, were determined in a way that all of the particles in a feasible space should be the answer to the capacity determination problem.

\subsection{Distribution of Renewable Energies}

For analysis of stochastic renewable energies and loads with proposed method, we require the probability distribution of wind speed, solar radiation and loads. In order to consider stochastic power generation of renewable energies, probability distributions of wind speed and sun radiation are analyzed. In order to analyze probability change of these parameters such as wind speed and solar radiation, PDF of parameters is used. In this section, wind speed and solar radiation are considered as suitable model of PDF for hourly data and parameters of considered PDF model for per hour determination. Firstly, the algorithm for determining PDF wind speed is described, and then density function of solar radiation is analyzed. For determining density function, model of Gaussian Distribution Method or other methods were used [7].

\subsubsection{Wind Energy Distribution Model}

The following method for Wind Speed Data was performed and log normal distribution is selected according to Figure 1, as a suitable model for hourly wind speed density function. This model has minimum error compared to other distribution and maximum suitable estimate in hours.

\subsubsection{Solar Energy Distribution Model}

The determining procedure for PDF of solar radiation is like, determination of the wind speed probability density function. With the difference that solar radiation rate in some hours of day is zero, there is no need to calculate the probability density function for these hours. Figure 2 shows this distribution.

\subsubsection{Load Distribution Model}

Sometimes for expressing the Power Demand Probability Model, previous studies used Normal Distribution [8]. We consider the uncertainty of load and the normal

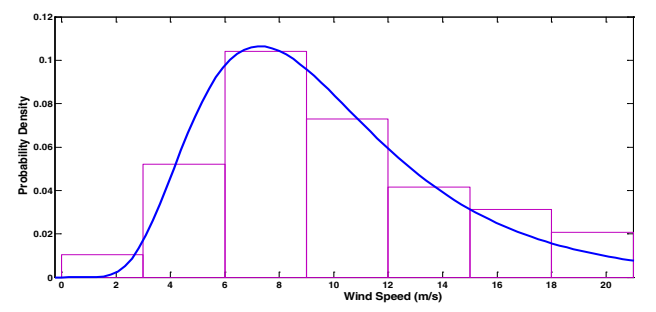

Figure 1. Distribution of lognormal estimates for an hour wind speed data. 


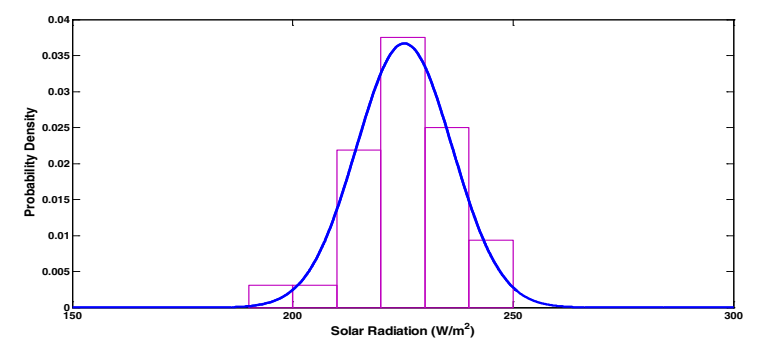

Figure 2. Distribution of normal estimates for an hour solar radiation data.

distribution changes for hourly basis over a period of one year.

\subsection{Combination of Wind-photovoltaic and Battery}

One of the useful and applicable combination structures for renewable energies, non-renewable energies in combination of wind, solar and battery is considered. Figure 3 illustrates this proposed combination method.

The Wind Turbine Model used, is of the type BWC Excel-R/48. Required changes in power-wind speed curve is considered by environmental situations from place of installed turbine according to Figure 4 and following equations. Wind speed data are measured in height of 25 meters from earth, average temperature $300(\mathrm{k})$ degrees, air density $1.225\left(\frac{\mathrm{kg}}{\mathrm{m}^{3}}\right)$ and average air pressure 100.814 (KPA). Output power of wind unit is calculated according to following equation:

$$
\mathrm{P}_{\mathrm{w}}(\mathrm{v})=\left\{\begin{array}{lr}
\mathrm{P}_{\mathrm{R}} \cdot \frac{\mathrm{v}-\mathrm{v}_{\mathrm{c}}}{\mathrm{v}_{\mathrm{R}}-\mathrm{v}_{\mathrm{c}}} & \mathrm{v}_{\mathrm{c}} \leq v \leq \mathrm{v}_{\mathrm{R}} \\
\mathrm{P}_{\mathrm{R}} & \mathrm{v}_{\mathrm{R}} \leq v \leq \mathrm{v}_{\mathrm{F}} \\
0 & v \leq \mathrm{v}_{\mathrm{c}} \text { and } v \geq \mathrm{v}_{\mathrm{F}}
\end{array}\right.
$$

where, $V_{c}$ is cut in speed, $V_{f}$ is the cut-off speed and $V_{R}$ is the rated speed and $P_{R}$ is the rate power. So, at first, it indicates how to calculate the output power of the wind and then effects of the independent variables relating to the relations of power output can be explained. These factors have a significant influence to obtain maximum power from wind units. Output power of wind unit is calculated as follows:

$$
P_{\text {wind }}=0.5 \cdot \rho \cdot A \cdot V^{3} \cdot C_{p}(\lambda, \beta)
$$

In this equation, $\rho$ is an air density, its unit being $\left(\frac{\mathrm{kg}}{\mathrm{m}^{3}}\right)$,

$A$ is the place where change by blades and its unit is $\left(m^{2}\right)$,

$V$ is the wind speed with unit of $\left(\frac{m}{s}\right)$,

$C_{p}$ is called the rotor efficiency.

Table 1 shows the parameters of the wind turbine and unit costs.

\begin{tabular}{|c|c|c|c|c|}
\hline $\begin{array}{l}\text { Lower } \\
\text { speed } \\
\text { limit } \\
(\mathrm{m} / \mathrm{s})\end{array}$ & $\begin{array}{c}\text { Speed } \\
\text { limit } \\
\text { over } \\
(\mathrm{m} / \mathrm{s})\end{array}$ & $\begin{array}{l}\text { Nominal } \\
\text { speed }\end{array}$ & $\begin{array}{c}\text { Output } \\
\text { power } \\
\text { maximum } \\
(\mathrm{kW})\end{array}$ & $\begin{array}{c}\begin{array}{c}\text { Power } \\
\text { over } \\
\text { speed } \\
\text { limit } \\
(\mathrm{kW})\end{array} \\
\end{array}$ \\
\hline$V_{\text {cutin }}$ & $V_{\text {cutout }}$ & $V_{\text {rated }}$ & $P_{\max }$ & $P_{\text {furl }}$ \\
\hline 3 & 25 & 13 & 8.1 & 6 \\
\hline $\begin{array}{l}\text { Height } \\
\text { of WGs } \\
\text { hub } \\
\text { (m) }\end{array}$ & $\begin{array}{c}\text { Capital } \\
\text { cost } \\
(\$ / \\
\text { Unit })\end{array}$ & $\begin{array}{c}\text { Replacement } \\
\text { cost } \\
(\$ / \text { Unit })\end{array}$ & $\begin{array}{l}\text { Operation } \\
\text { and } \\
\text { maintenance } \\
\text { cost } \\
\text { (\$/Unit- } \\
\text { year) }\end{array}$ & $\begin{array}{c}\text { life } \\
\text { time } \\
\text { of } \\
\text { wind } \\
\text { unit } \\
\text { (Year) }\end{array}$ \\
\hline $\mathrm{H}$ & $\mathrm{CC}_{\mathrm{w}}$ & $\mathrm{RC}_{\mathrm{w}}$ & $\mathrm{O} \& \mathrm{MC}_{\mathrm{W}}$ & $\mathrm{Y}_{\mathrm{w}}$ \\
\hline 19.9526 & 16400 & 13000 & 75 & 20 \\
\hline
\end{tabular}

Table 1. Parameters and costs of wind [13]

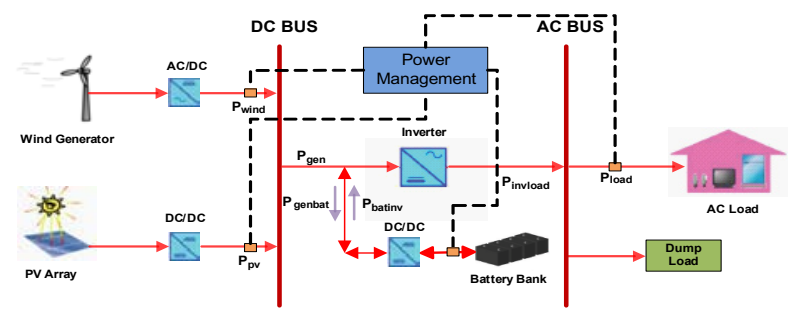

Figure 3. Hybrid renewable sources.

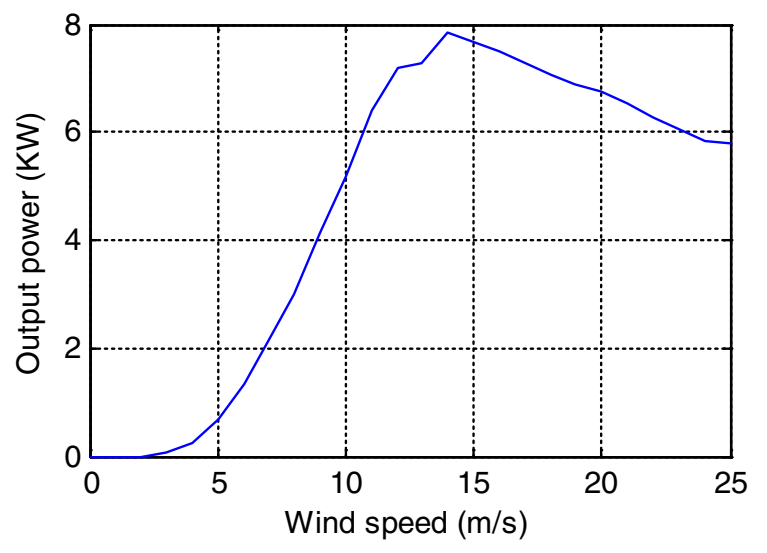

Figure 4. Wind turbine power curve. 
There are different equations for calculating power generation photovoltaic unit. One of the equations for calculating output power of $\mathrm{PV}$ cell is as follows:

$$
P_{\text {solar }}=\frac{G}{G_{\text {ref }}} P_{\text {solar. ref }} \cdot \eta_{\text {solar }}
$$

In this equation, $G_{r e f}$ is solar radiation at standard condition and $P_{\text {solar ref }}$ is rated power of each array(KW) and $\eta_{\text {solar }}$ is the DC/DC converter efficiency installed between each cell and DC bus bar. In the above equations, the amount of the radiation is the total radiation that has been treated to an array. If the horizontal and vertical components of the radiation array are present in every moment, radiation can be calculated with the following equation [9]:

$$
G=G_{v} \cos \left(\theta_{p v}\right)+G_{H} \sin \left(\theta_{p v}\right)
$$

here, $G_{V}$ and $G_{H}$, respectively, the horizontal and vertical radiation levels hourly and $\theta_{p v}$, the angle of the solar panel towards the horizon which varies in the range of 0 to 90. Maximum Power Point of the $P V$ cell in standard situation or the Rated Power of used $P V$ cell in this simulation is $1(\mathrm{KW})$. Table 2 illustrates parameters and costs of PV cell.

The model battery used in simulations is from type Surrette- 6CS25P $[10,11]$. Parameters and costs of this battery are illustrated in Table 3.

Table 2. Parameters and costs related to solar units

\begin{tabular}{llc}
\hline $\begin{array}{l}\text { Radiation Nominal } \\
\text { at standard } \\
\text { conditions } \\
\left(\mathrm{W} / \mathrm{m}^{2}\right)\end{array}$ & $G_{\text {ref }}$ & 1000 \\
$\begin{array}{l}\text { Efficiency of } \\
\text { inverter DC/DC }\end{array}$ & $\eta_{\text {solar }}$ & $\% 90$ \\
$\begin{array}{l}\text { Solar power } \\
\text { nominal }(\mathrm{kW})\end{array}$ & $P_{\text {solar.ref }}$ & 1 \\
$\begin{array}{l}\text { Capital cost } \\
\text { (\$/Unit) }\end{array}$ & $\mathrm{CC}_{\mathrm{S}}$ & 7000 \\
$\begin{array}{l}\text { Replacement cost } \\
\text { (\$/Unit) }\end{array}$ & $\mathrm{RC}_{\mathrm{S}}$ & 6000 \\
$\begin{array}{l}\text { Operation and } \\
\text { maintenance cost } \\
\text { (\$/Unit-year) }\end{array}$ & $\mathrm{O} \& \mathrm{MC}_{\mathrm{S}}$ & 20 \\
$\begin{array}{l}\text { Life time of } \\
\text { photovoltaic array } \\
\text { (Year) }\end{array}$ & $\mathrm{Y}_{\mathrm{S}}$ & \\
\hline
\end{tabular}

Table 3. Parameters and costs related to battery units

\begin{tabular}{llr}
\hline $\begin{array}{l}\text { Rate voltage } \\
\text { (Volt) }\end{array}$ & $V$ & 6 \\
Rated battery capacity (kWh) & $E_{\text {Batrated }}$ & 6.94 \\
& $\mathrm{DOD}$ & $\% 80$ \\
Depth of Discharge & $\mathrm{CC}_{\mathrm{B}}$ & 1250 \\
Replacement cost (\$/Unit) & $\mathrm{RC}_{\mathrm{B}}$ & 1100 \\
Replacement cost (\$/Unit) & 20 \\
Operation and maintenance cost & ${\mathrm{O} \& \mathrm{MC}_{\mathrm{B}}}^{\text {(\$/Unit-year) }}$ & \\
Life time of battery (Year) & $\mathrm{Y}_{\mathrm{B}}$ & 4 \\
\hline
\end{tabular}

\section{Formulating Problem}

The cost minimization of combined system and reliability improvement is considered as an objective function.

\subsection{Combination System Cost Analysis}

Net Present Cost (NPC) was used for modeling all the costs [12]. NPC is calculated by using equation (5). [13]

$$
N P C=\sum_{i=1}^{L} N_{i}\left(C C_{i}+R C_{i} * K_{i}+O \& M C_{i} * P W A(\text { ir. } R)\right)
$$

$\mathrm{L}$ is the number of used units in combination of units. For example, in combination of wind units, solar and battery, $L$ is assumed to be equal to $3 . N_{i}$ is the number of renewable units or $i^{\text {th }}$ storage unit, and this parameter is determined by optimization algorithm. $C_{i}$ is the cost of $i^{\text {th }}$ unit by $\left(\frac{S}{\text { unit }}\right), R C_{i}$ is the cost of $i^{\text {th }}$ unit changing by $\left(\frac{S}{\text { unit }}\right)$ and $O \& M C_{i}$ is the cost of $i^{\text {th }}$ unit operation and maintenance by $\left(\frac{S}{\text { unit-year }}\right)$. In NPC Model, all of the costs should be adapted to first year project. In order to change the cost to first year of project, $K_{i}$ coefficient is used. In fact, $K_{i}$ is a coefficient of $i^{\text {th }}$ unit that changes the cost in future to equivalent cost of the future. $K_{i}$ is illustrated by using the following equations [13]:

$$
\mathrm{K}_{\mathrm{i}}=\sum_{\mathrm{n}=1}^{\mathrm{L}_{1}} \frac{1}{(1+\mathrm{ir})^{\mathrm{n} . \mathrm{L}_{2}}}
$$

where, ir is the interest rate, considered as a constant value equal to 0.06 [13] in this paper.

$L_{2}$ is total life time of $i^{\text {th }}$ renewable unit by year and

$L_{1}$ is the number of time that unit replaced in its life time. 
If Project Lifetime (R) per year, over the life time of unit $\left(L_{2}\right)$, is desirable, $L_{1}$ is calculated according to (7) and if these two parameters are non-dividable, $L_{1}$ is calculated according to (8).

If the unit life time is greater or equal to project life time, the value $k_{1}$ is considered to be 0 . It means that replacing cost is not considered.

$$
\begin{gathered}
L_{1}=\left[\frac{R}{L_{2}}\right]-1 \\
L_{1}=\left[\frac{R}{L_{2}}\right]
\end{gathered}
$$

Cost of operation, repair and maintenance are expressed annually. For returning this cost to its equivalent cost in its initial year projects in order to use on the cost model of coefficient PWA is used. In fact, this coefficient converts annual operation cost, repair and maintenance over the life of project to equivalent cost in startup of project. PWA is defined as follows. This coefficient depends on Interest Rate (IR) and the project life time (R). [13]

$$
\operatorname{PWA}(i r, R)=\frac{(1+i r)^{\mathrm{R}}-1}{\operatorname{ir}(1+\mathrm{ir})^{\mathrm{R}}}
$$

According to equation (5) for each unit, capital cost, replacement cost, operation and maintenance is calculated from the above equations and the number of units from the proposed optimization algorithm is calculated. The total cost for all units creates net present value.

\subsection{Reliability Index}

Reliability Indexes such as Equivalent Loss Factor (ELF) is used. Equation (10) will represent this index.

$$
E L F=\frac{1}{N} \sum_{t=1}^{N} \frac{Q(t)}{D(t)}
$$

In this equation,

$D(t)$ is the load demand at time step $t^{\text {th }}$

$Q(t)$ is the not provided load at time step $t^{\text {th }}$ and

$N$ is the total number of time steps.

This index contains information such as, the number of supply interruptions and no supply of energy at each time step. Advantage is taken of this index in algorithms that determine their capacity with regard to uncertainty or without regard of uncertainty is possible. For this reason, equivalent loss factor is appropriate index for such issues. The maximum equivalent loss factor allowable rate equivalent for system for grid connected system in developed countries is 0.0001 and this index is considered to be 0.1 for independent grid systems [14].

\subsection{Power Management}

To evaluate supply loads and changes in charge and discharge mode of storage system, energy management strategy is required. In combination of renewable units with storage elements and non-renewable units, energy management is often considered, so that priorities in supply load are the use of renewable units of electric power generation. If generated power of renewable units is more than consumption load, excess electric power production is stored in battery with regard to limitations of storage battery. If generated power of renewable units is less than consumption load, shortage of electric power consumed is supplied by considering limitation of storage elements; if these elements are not able to supply enough electric power consumption, some of the load is disconnected.

\section{Proposed Method}

In this section, after describing model and required indexes to evaluate this algorithm the proposed algorithm for determining the capacity of renewable energies is expressed. In proposed algorithm, hourly data of consumed power is used and study is based on hourly data for a period of one year. Limitations of battery charge mode, maximum and minimum of battery charge has been considered and also equality constraints of battery charge mode in early and last hours is considered. A sequential Monte Carlo method was used to determine the capacity of hybrid wind, solar and storage battery units considering uncertainty of wind and solar power.

Proposed algorithm for Monte Carlo method after generation of probability density function of wind speed and solar radiation and consumption load, initial population is determined. The initial population must be defined so that all particles in feasible space should determine the capacity problem. For this reason, after the production of each particle, first reliability index with considering uncertainty of distributed generation units is calculated. If the reliability index is in the feasible space problem, this particle is in total population. This process continues 
until the desired initial population. For determining the reliability index, the algorithm starts from the first hour of the day in year. At the beginning of algorithm the assumption is that the battery is fully charged. In this method to calculate $\mathrm{Q} / \mathrm{D}$, the average of $\mathrm{Q} / \mathrm{D}$ and average of new state battery charge are adopted per hour. For the first hour, wind speed and sun radiation are generated using probability density function of wind speed, sun radiation, consumed load.

Using the relationship between wind and solar power units and from number of units that has been established from the optimization algorithm, total production of each unit is calculated.

Ratio of not supplied load to supplied load and new state of battery charge mode are explained by energy management and generated power data is calculated. Then this process is repeated several times per hour. At any time the average ratio of not supplied load to supplied load and new state of battery charge is calculated. The average difference for each of these factors was calculated in two successive iterations. If the difference is less than 0.0001 , find average value if these two factors are considered as the ratio of not supplied load to supplied load and new mode of battery charge for this hour. This process is repeated for next hours and in any hour ratio of not supplied load to total supplied load and new state of battery charge is determined. At last reliability index is described using equation (11).

$$
E L F=\frac{1}{N} \sum_{t=1}^{N} E \frac{Q(t)}{D(t)}
$$

In this equation, $E \frac{Q(t)}{D(t)}$ is the average ratio at not supplied load to supplied load in $\mathrm{t}$ seconds. After determining reliability index and cost for any particle, the best experience of particles and best experience of group is designated. Then considering illustrated equations for determining new position particle, new state of particle is determined. Reliability index is calculated for new particle. If the new particle is not in the feasible place of answer, it will be updated to occur then. This process is repeated for all particles for any iteration and in the final iteration, optimal number of wind, solar and battery are determined.

\subsection{PSO Algorithm}

In PSO algorithm, after finding the best location $\left(\mathrm{P}_{\text {best }}\right)$ and the best experience group $\left(G_{\text {best }}\right)$ that the particle experiences, new speed $V_{n}^{(i+1)}$ and new location $\left(X_{n}^{(i+1)}\right)$ is determined by these relationships $[1,3]$.

$$
\begin{gathered}
V_{n}^{i+1}=\omega V_{n}^{i}+C_{1} \text { rand }\left(P_{\text {best }_{n}}-X_{n}^{i}\right) \\
+C_{2} \text { rand }\left(G_{b e s t_{n}}-X_{n}^{i}\right) \\
X_{n}^{i+1}=X_{n}^{i}+V_{n}^{i+1}
\end{gathered}
$$

In this equation, $X_{n}^{i}$ position of $n^{\text {th }}$ particle in $i^{\text {th }}$ iteration, $V_{n}^{i}$ particle speed $n^{\text {th }}$ in $i^{\text {th }}$ iteration, rand is a random number between zero and one and, $C_{1}$ and $C_{2}$ is acceleration coefficient and $\omega$ is inertia coefficient. $\omega$ represents the inertia of particle. The high amount inertia makes it easy to explore (searching in new areas for increasing reliability) and small amount for increase accuracy (accurate search in a specific area). In PSO algorithm used in this paper, the inertia coefficient is calculated from the following equations:

$$
\omega=\omega_{\max }-\left(\frac{\omega_{\max }-\omega_{\min }}{\text { iter }_{\max }}\right) * i \text { ter }
$$

In the above equation $\omega_{\min }$ and $\omega_{\max }$ is the maximum and minimum coefficient considered for $\omega$, iter represent number of repeat, iter ${ }_{\text {max }}$ illustrates maximum repeat considered for algorithm. Coefficient $C_{1}$ and $C_{2}$ are Learning rate or increasing speed (particle acceleration) that pushed the particle to $\mathrm{G}_{\text {best }}$ and $\mathrm{P}_{\text {best }}$. Table 4 shows the parameters of PSO optimization algorithm.

\section{Simulation Results}

In this paper, the hybrid of solar, wind and battery for supply the load as shown in Figure 5 is considered. Maximum power consumed and project life times are assumed to be $500 \mathrm{KW}$ and 20 years respectively. Analysis of capacity determination with Monte Carlo method, result optimized combination have an equivalent loss factor equal to 0.1. 22 years hourly data of wind speed and sun radiations are used with time speed twohour and this study is done for the region near shore in North America.

Table 4. Parameters for PSO optimization algorithm

\begin{tabular}{ccccccc}
\hline Population & $\begin{array}{c}\text { number } \\
\text { of repeat }\end{array}$ & $\mathrm{C}_{1}$ & $\mathrm{C}_{2}$ & $\omega_{\max }$ & $\omega_{\min }$ & $\mathbf{k}$ \\
\hline 50 & 100 & 1.5 & 1.5 & 1 & 0.1 & 0.5 \\
\hline
\end{tabular}




\subsection{Simulation with Loads of Sources of Uncertainty}

The simulation was performed several times using different initial values and converging optimization algorithm with three different implementation is shown in Figure 6. As can be seen from this figure, the response is independent of the initial value obtained which is the same in each case. Table 5 shows the optimum values obtained for the total cost of wind, solar and storage battery. The problem of determining the capacity of the Monte Carlo method, the optimal combination of Equivalent Loss Factor (ELF) is 0.1 and repeat until convergence of the optimization algorithm have been few signs of 35 repetitions.

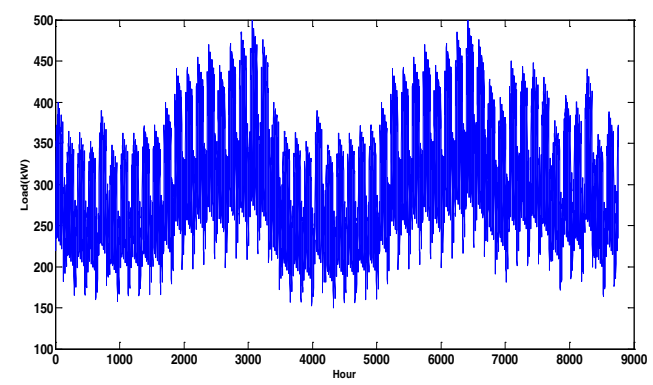

Figure 5. Electric power consumption for one year.

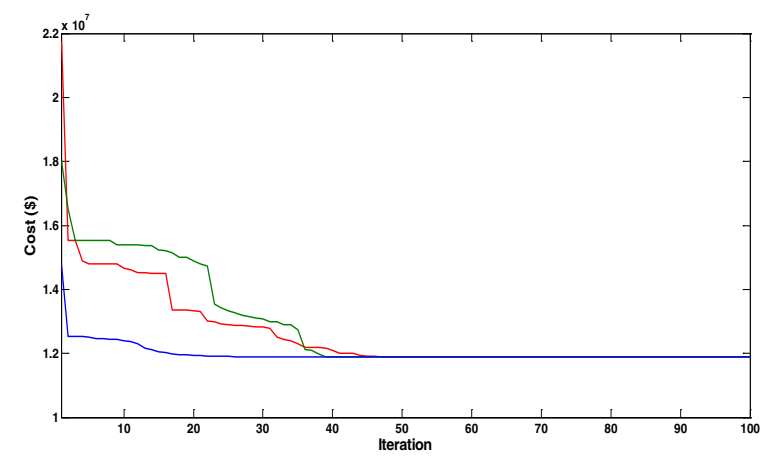

Figure 6. Convergence of PSO optimization algorithm.

Table 5. Optimized parameters and cost of hybrid wind, solar and battery with Monte Carlo method

\begin{tabular}{cccc}
\hline $\begin{array}{c}\text { Number of } \\
\text { wind unit } \\
\mathrm{N}_{\mathrm{w}}\end{array}$ & $\begin{array}{c}\text { Number of } \\
\text { solar unit } \\
\mathrm{N}_{\mathrm{S}}\end{array}$ & $\begin{array}{c}\text { Number of } \\
\text { battery } \\
\mathrm{N}_{\mathrm{B}}\end{array}$ & $\begin{array}{c}\text { Total } \\
\text { cost } \\
\left(10^{6} \$\right)\end{array}$ \\
\hline 350 & 301 & 912 & 11.884 \\
\hline
\end{tabular}

\subsection{Simulation without Considering Uncertainty Load and Sources}

The averages of two hours of wind speed and solar radiation data have been used to calculate wind and solar power generation units. Then by utilizing Modified Particle Swarm Optimization Algorithm (MPSO), cost model, energy management strategy and reliability indices which have been previously defined, the calculation of the optimal number of units of wind, solar and battery storage, is conducted regardless of the uncertainty of output powers of wind and solar units.

Figure 7 and Table 6, respectively, shows the convergence optimal algorithm and optimizing parameters such as the units of wind, solar and battery storage in a state of determining capacity problem, without considering uncertainty in the renewable energy. The optimization algorithm in this method in the repeat of $48^{\text {th }}$ with reliability index 0.1 is converged to the optimal values.

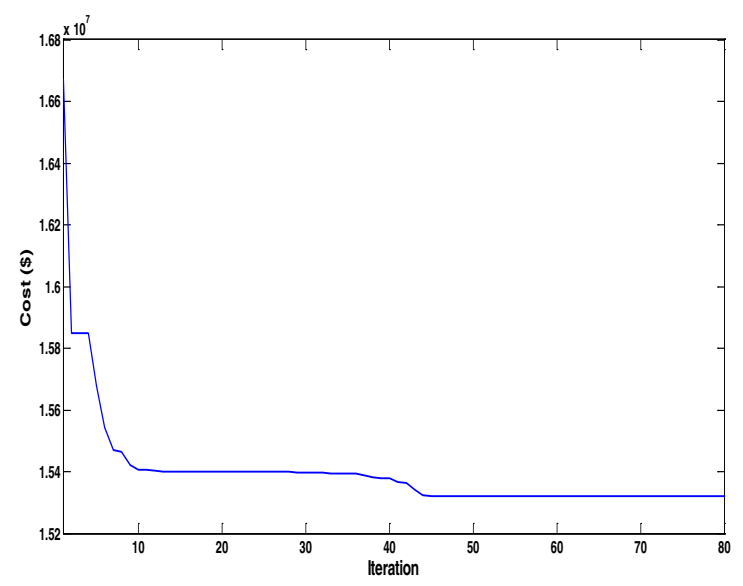

Figure 7. Convergence of the PSO optimization algorithm without considering the uncertainties of renewable energy.

Table 6. Optimized parameters and cost of hybrid wind, solar and storage battery without considering uncertainties of renewable energies

\begin{tabular}{cccc}
\hline $\begin{array}{c}\text { Number of } \\
\text { wind unit } \\
\mathrm{N}_{\mathrm{W}}\end{array}$ & $\begin{array}{c}\text { Number of } \\
\text { solar unit } \\
\mathrm{N}_{\mathrm{S}}\end{array}$ & $\begin{array}{c}\text { Number of } \\
\text { battery } \\
\mathrm{N}_{\mathrm{B}}\end{array}$ & $\begin{array}{c}\text { Total } \\
\text { cost } \\
\left(10^{6} \$\right)\end{array}$ \\
\hline 375 & 823 & 721 & 15.321 \\
\hline
\end{tabular}




\subsection{The Analysis of the Effect of Equivalent Loss Factor on the Determining Capacity}

Determining the capacity of hybrid wind, solar and battery storage for equivalent loss factor of $0.05,0.08,0.1$ and 0.15 is done with the use of method Monte Carlo and the results shown in Table 7.

\subsection{The Analysis of the Sensitivity of Determining Capacity than Parameters Change Probability Density Function Wind Speed and Solar Radiation}

With the 1 percent and 10 percent changes on Coefficients Probability Density Function of wind speed and solar radiation, the decrease in cost was 4.2 and 28.7 percent respectively and Equivalent Loss Factor (ELF) calculated for Optimal hybrids with using Monte Carlo method was $13 / 87$ and $114 / 75$ percent respectively which is more than equivalent loss factor of 0.1 . The results are given in Table 8. Interestingly, the method proposed here is not restricted to the units combining wind, solar and battery storage but also applicable to any combination of renewable and non-renewable units.

\section{Conclusion}

The optimal determination capacity problem of distributed energy resources of stand-alone power system was proposed. The uncertainty of wind turbine and solar array output power on determining capacity of hybrid wind, solar and battery is taken into account. Simulations are performed in two methods. In the first method, the uncertainty of wind speed and solar radiation is not counted while in the second one it is taken into consideration. To compare the above-mentioned methods, cost and reliability are taken as indices. Objective function for these methods is cost, which is calculated with NPC procedure and ELF as the constraint of the optimization algorithm. Simulation results point out that if renewable energy uncertainty is not considered, the project cost will be 29 percent higher than the state cost when uncertainty is taken into account (with specific Environmental and climate conditions).

Considering the uncertainty of the determining capacity of renewable energy is a realistic vision. In this study, the analysis is conducted on determining capacity of hybrid wind, solar and storage battery. The obtained results are as below:
Table 7. Optimized parameters and cost of hybrid wind, solar and storage battery with method Monte Carlo for equivalent loss factor different

\begin{tabular}{ccccc}
\hline $\begin{array}{c}\text { Equivalent } \\
\text { Loss Factor } \\
\text { ELF }\end{array}$ & $\begin{array}{c}\text { Number } \\
\text { of wind } \\
\text { unit } \\
\mathrm{N}_{\mathrm{W}}\end{array}$ & $\begin{array}{c}\text { Number } \\
\text { of solar } \\
\text { unit } \\
\mathrm{N}_{\mathrm{S}}\end{array}$ & $\begin{array}{c}\text { Number } \\
\text { of } \\
\text { battery } \\
\mathrm{N}_{\mathrm{B}}\end{array}$ & $\begin{array}{c}\text { Total cost } \\
\left(\mathbf{1 0 ^ { 6 }} \mathbf{\$}\right)\end{array}$ \\
\hline 0.05 & 430 & 353 & 1063 & 14.244 \\
0.08 & 407 & 260 & 967 & 12.792 \\
0.1 & 350 & 301 & 912 & 11.884 \\
0.15 & 271 & 349 & 704 & 10.031 \\
\hline
\end{tabular}

Table 8. Optimized parameters and cost of hybrid wind, solar and storage battery determining by probability method with considering changes in the coefficient of probability density function of wind and solar units

\begin{tabular}{crrrc}
\hline $\begin{array}{c}\text { Increase } \\
\text { Coefficient }\end{array}$ & $\mathrm{N}_{\mathrm{w}}$ & $\mathrm{N}_{\mathrm{S}}$ & $\mathrm{N}_{\mathrm{B}}$ & Total cost \\
\hline 0.01 & 414 & 56 & 954 & 11.386 \\
0.1 & 307 & 0 & 787 & 8.4631 \\
\hline
\end{tabular}

The cost change rate of solving the specifying capacity problem with regard to different reliability indices (ELF) indicates that, it is feasible to spend less expanse in comparison with the total expenditure and on the other hand, it is possible to get a concrete increase in system reliability (i.e, ELF is less) results paper show that considering the uncertainty decrease the cost with the same reliability index When the uncertainty is not considered.

\section{References}

1. Yang $\mathrm{H}, \mathrm{Lu} \mathrm{L}$ et al. (2007). A novel optimization sizing model for hybrid solar-wind power generation system, Solar Energy, vol 81(1), 76-84.

2. Wang C, and Nehrir M H (2008). Power management of a stand-alone wind/photovoltaic/fuel cell energy system, IEEE Transactions on Energy Conversion, vol 23(3), 957-967.

3. Wang L, and Singh C (2009). Multicriteria design of hybrid power generation systems based on a modified particle swarm optimization algorithm, IEEE Transactions on Energy Conversion, vol 24(1), 163-172.

4. Bilal B O, Sambou V et al. (2010). Optimal design of a hybrid solar-wind-battery system using the minimization of the annualized cost system and the minimization 
of the Loss of Power Supply Probability (LPSP), Renewable Energy, vol 35(10), 2388-2390.

5. Kaabeche A, Belhamel M et al. (2011). Sizing optimization of grid-independent hybrid photovoltaic/wind power generation system, Energy, vol 36(2), 1214-1222.

6. Grimsmo L, Korpås M et al. (2004). A probabilistic method for sizing of isolated wind-electrolyzer systems, 4 th Nordic Workshop on Power and Industrial Electronics.

7. Sasaki H, Nakashima M et al. (1978). A bad data detection algorithm in power system state estimation, Electrical Engineering in Japan, vol 98(5), 108-115.

8. Rubinstein R Y, and Kroese D P (2007). Simulation and the Monte Carlo Method, 2nd Edn., Wiley Interscience, Hoboken, New Jersey, 82-103.

9. Kaviani A K, Baghaee H R et al. (2007). Design and optimal sizing of a photovoltaic/wind generator system using particle swarm optimization, 22nd Power System Conference (PSC), 19-21.

10. Navaeefard A, Tafreshi S M M et al. (2010). Optimal sizing of distributed energy resources in microgrid considering wind energy uncertainty with respect to reliability, IEEE International Energy Conference and Exhibition, 820-825.

11. Surrette Battery Company Limited, Available from: http://www.rollsbattery.com/content/battery-usermanual/

12. Haghi H V, Hakimi S M et al. (2010). Optimal sizing of a hybrid power system considering wind power uncertainty using particle swarm optimization-embedded stochastic simulation, 2010 IEEE 11th International Conference on Probabilistic Methods Applied to Power Systems (PMAPS), 722-727.

13. Jahanbani Ardakani F, Riahy G et al. (2010). Design of an optimum hybrid renewable energy system considering reliability indices, 2010 18th Iranian Conference on Electrical Engineering (ICEE), 842-847.

14. Karki R, and Bilinnton R (2001). Reliability/cost implication of pv and wind energy utilization in small isolated power system, IEEE Transactions on Energy Conversion, vol 16(4), 368-373. 